\title{
Manajemen Sarana dan Prasarana Taman Penitipan Anak di Lampung
}

\author{
Romlah $^{1}$, Rumadani Sagala ${ }^{2}$ \\ Pendidikan Islam Anak Usia Dini, Universitas Islam Negeri Raden Intan Lampung, Indonesia(1) \\ Pendidikan Bahasa Arab, Universitas Islam Negeri Raden intan Lampung, Indonesia(2) \\ DOI: $\underline{10.31004 / o b s e s i . v 6 i 1.1207}$
}

\begin{abstract}
Abstrak
Terpenuhinya sarana dan prasarana pada lembaga taman penitipan anak (TPA) yang memadai dan berkualitas berpengaruh pada tumbuh kembang anak usia dini. Fokus penelitian ini mengkaji proses manajemen sarana dan prasarana yang meliputi perencanaan (planning), pengoranisasian (organizing), pelaksanaan (actuating) dan pengawasan (controlling) (POAC) di TPA Pinggungan Sebuai dan TPA Cut Muthia. Metode penelitian ini menggunakan pendekatan kualitatif dengan desain penelitian studi kasus. Teknik pengumpulan data menggunakan teknik wawancara, observasi dan dokumentasi. Analisis data dengan cara reduksi data, penyajian data dan penarikan kesimpulan sedangkan pengecekkan keabsahan data menggunakan triangulasi. Hasil analisis terkait kegiatan manajemen POAC di TPA Pinggungan Sebuai dan TPA Cut Muthia dilakukan dengan mengikuti setiap prosedur manajemen POAC dan secara umum sudah dilaksanakan dengan baik. Oleh karena itu, dengan meningkatkan kembali manajemen sarana dan prasarana melalui kegiatan manajemen yang tepat pada taman penitipan anak menjadi salah satu sumber daya yang penting dalam menunjang proses tumbuh kembang anak usia dini.
\end{abstract}

Kata Kunci: manajemen pendidikan; manajemen sarana dan parasaranai; taman penenitipan anak.

\begin{abstract}
The availability of high-quality facilities and infrastructure at daycare institutions (TPA) affects early childhood development. This research aims to examines the facility and infrastructure management process which includes planning, organizing, actuating, and controlling (POAC) at the TPA Pinggungan Sebuai and TPA Cut Muthia. The qualitative approach with a case study research design is employed in this research. The data are collected through interview, observation, and documentation. The data then analyzed through data reduction, data presentation, and drawing conclusions. Triangulation techniques are utilized to check the validity of the data. The results of the analysis related to the POAC management activities at the TPA Pinggungan Sebuai and TPA Cut Muthia were carried out by following each POAC management procedure and were generally well implemented. Therefore, by improving the management of facilities and infrastructure through proper management activities in child care parks, it is one of the important resources in supporting the process of early childhood development and development.
\end{abstract}

Keywords: education management; management of facilities and infrastructure; nursery garden

Copyright (c) 2021 Romlah, Rumadani Sagala

$\triangle$ Corresponding author:

Email Address : Romlah@radenintan.ac.id (Lampung, Indonesia)

Received 19 March 2021, Accepted 15 April 2021, Published 19 April 2021 


\section{PENDAHULUAN}

Pembelajaran saat ini fokus pada perkembangan ilmu pengetahuan serta teknologi (Koedel et al., 2019; Pricilia et al., 2020; Trianingsih et al., 2020). Dimana teknologi semakin pesat berkembang dan semakin mudah diakses setiap orang, mulai dari anak berusia dini hingga orang dewasa (Kustiawan \& Enggarwati, 2021; Yula Anggriani, 2020). Sebagai orang tua yang paham terkait perkembangan zaman harus lebih berhati-hati terhadap pendidikan dan tumbuh kembang anak sejak dini (Agustina, 2019; Beauvais, 2016). Salah satu pendidik pertama yang diharapkan mampu mengembangkan aspek perkembangan anak usia dini adalah orang tua dan keluarga (Rohmani, 2020).

Namun saat ini banyak orang tua yang semestinya menjadi pendidik utama dalam kegiatan pembelajaran di rumah kini lebih banyak yang bekerja di luar rumah dan menggantikan posisinya dengan tenaga pengasuh anak (Falhatunnisa et al., 2020; Hardiyanti, 2020). Semakin berkembanganya zaman tenaga pengasuh anak saat ini semakin sulit didapatkan, dan terkadang pola asuh yang diterapkan oleh pengasuh anak belum tentu mengasuh anak usia dini dengan baik (Brebner et al., 2015; O'Hara, 2010). Alternatif dalam mengatasi permasalahan ini salah satunya menitipkan anak pada jalur pendidikan non resmi ialah Taman Penitipan Anak (TPA) (Plum, 2017; Rizkita, 2017). Sebagai penyelengaraan program pendidikan sekaligus pengasuhan anak usia dini, TPA kini semakin dibutuhkan di kalangan masyarakat khususnya orang tua yang bekerja di luar rumah (Hamer et al., 2020; Oktaviana \& Utsman, 2015).

TPA harus sanggup menyelenggarakan program pembelajaran sekaligus pengasuhan yang bermutu sesuai dengan tumbuh kembang anak berusia dini (Esha \& Abtokhi, 2020; Lee, 2016; Riyadlotus Sholichah, 2020). Terwujudnya taman penitipan anak yang sesuai dengan standar pendidikan dapat dilihat dari sarana dan prasarananya (Junaidi \& Danim, 2020). Berlandaskan hasil observasi oleh peneliti bahwa salah satu yang menjadi faktor dalam perkembangan system pendidikan pada taman penitipan anak adalah sarana dan prasarananya. Dimana sarana dan prasarana menjadi peralatan dalam penyelenggaraan serta pengelolaan kegiatan pendidikan dan pengasuhan pada anak usia dini. Oleh karena itu manajemen sarana prasarana bertugas mengendalikan dan melindungi sarana dan prasarana pembelajaran agar menjadi fasilitas yang efektif dalam proses pendidikan (Parid \& Alif, 2020). Dalam kegiatan pengelolaan ini terdapat beberapa aktifitas manajemen yakni perencanaan, pengadaan, pengawasan, penyimpanan, inventaris, penghapusan serta penyusunan (Megasari, 2014; Ulfa et al., 2021). Selain itu, ada 4 proses manajemen yang sering digunakan menjadi alternatif dalam pengelolaan sarana dan prasaran diantaranya perencanaan (planning), pengoranisasian (organizing), pelaksanaan (actuating) serta pengawasan (controlling) (POAC) (Hadi, 2020; Rosmayati et al., 2021).

Senada dengan riset terdahulu mengenai manajemen sarana dan prasarana diantaranya manajemen sarana dan prasarana di day care baby's home Salatiga (Kusumawati, 2017). Kemudian manajemen sarana prasarana pendidikan anak usia dini di TK Pelangi Anak Negeri Yogyakarta (Binsa, 2021), serta analisis pedagogi berkualifikasi akademis dan nonakademis di pusat penitipan anak (Schmidt et alss., 2018). Adapun beda penelitian ini dengan penelitian sebelumnya penelitian ini mengkaji manajemen sarana dan prasarana di Taman Penitipan Anak (TPA) Kota Bandar Lampung studi kasus TPA Cut Muthia dan TPA Pinggungan Sebuai dari segi perencanaan (planning), pengoranisasian (organizing), pelaksanaan (actuating) dan pengawasan (controlling) yang disingkat POAC dimana penelitian sebelumnya belum menggunakan manajemen pengelolaan sarana dan prasarana dari segi POAC. Maka pentingnya penelitian ini dilakukan untuk memperoleh hasil kajian manajemen sarana dan prasarana dari segi POAC. 


\section{METODOLOGI}

Penelitian ini menggunakan metode kualitatif dengan desain studi kasus, yang mendalami suatu kasus tertentu secara lebih mendalam dengan melibatkan pengumpulan dari berbagai sumber informasi untuk menangkap kompleksitas sebuah kasus. Penelitian dilakukan pada dua lembaga terkait proses manajemen sarana dan prasarana yang meliputi perencanaan (planning), pengoranisasian (organizing), pelaksanaan (actuating) dan pengawasan (controlling) (POAC) di Taman Penitipan Anak (TPA) Pinggungan Sebuai dan TPA Cut Muthia Kota Bandar Lampung. Subjek utama sebagai informan dalam penelitian ini adalah kepala sekolah dan guru kelas sebagai subjek pendukung.

Teknik pengumpulan data yang digunakan dalam penelitian ini adalah wawancara, observasi, dan dokumentasi. Teknik analisis data yang digunakan adalah reduksi data, penyajian data, dan penarikan kesimpulan. Langkah untuk memperoleh kesimpulan yang tepat dalam penelitian ini dengan cara pengecekan keabsahan data, dalam pengecekan keabsahan data peneliti menggunakan teknik triangulasi. Berikut ini skema Teknik triangulasi data dapat dilihat ada gambar 1.

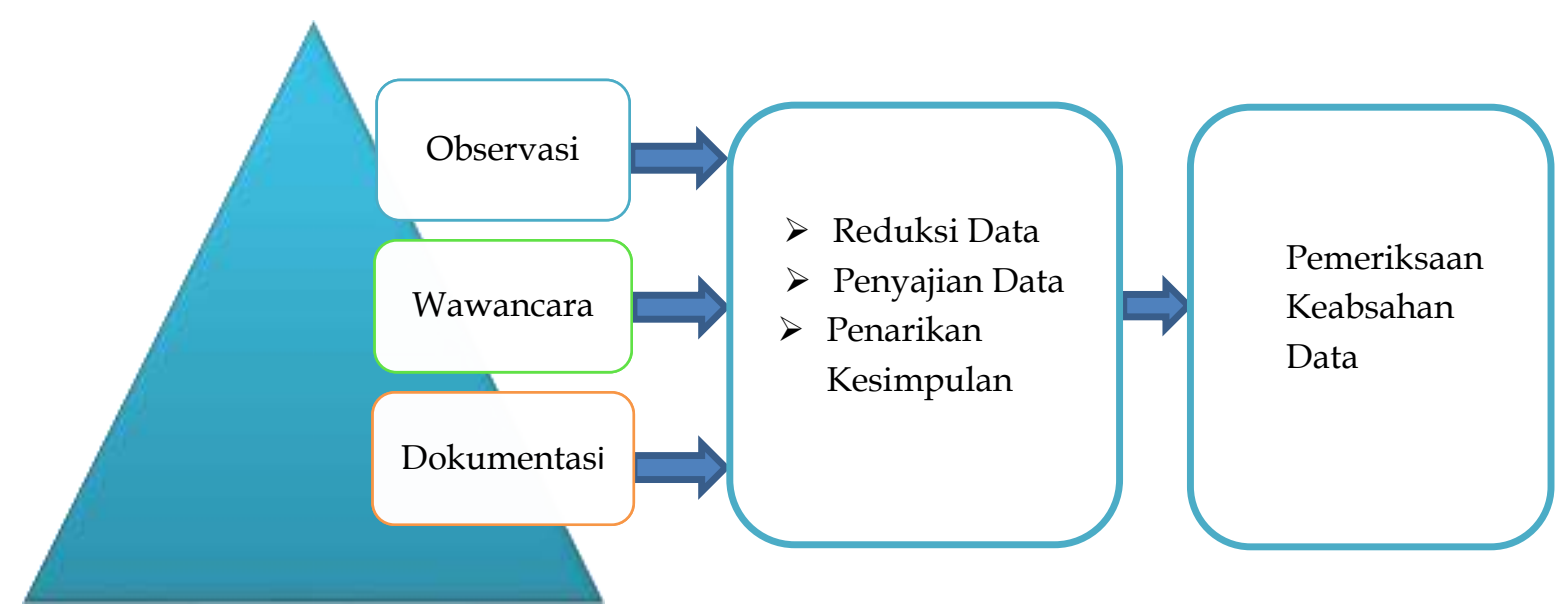

Gambar 1. Teknik Triangulasi Data

\section{HASIL DAN PEMBAHASAN}

Berdasarkan hasil penelitian yang telah dilakukan terkait manajemen sarana dan prasarana di Taman Penitipan Anak (TPA) Pinggungan Sebuai dan TPA Cut Muthia Kota Bandar Lampung meliputi kegiatan perencanaan (planning), pengorganisasian (organizing), pelaksanaan (actuating) dan pengawasan (controlling). Gambarannya dapat dilihat pada gambar 2.

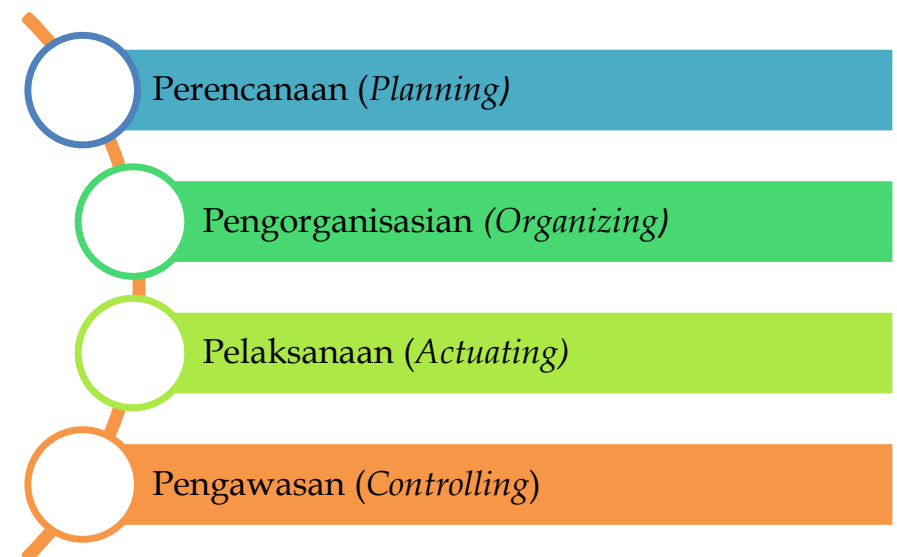

Gambar 2. Kegiatan Proses Manajemen POAC 
Tabel 1. Hasil Analisis Kegiatan Manajemen POAC

\begin{tabular}{ll}
\hline $\begin{array}{c}\text { Kegiatan Manajemen } \\
\text { POAC }\end{array}$ & Hasil Analisis \\
\hline Perencanaan & Hasil analisis pada perencanaan (planning) sarana dan prasarana di TPA Pinggungan Sebuai
\end{tabular}
(planning) Kota Bandar Lampung ini disusun bersumber pada seluruh usulan dari berbagai pihak seperti pendidik, tenaga pendidik serta wali murid yang kemudian akan diadakan rapat oleh pengelola lembaga TPA dimana pada rapat tersebut membahas terkait rencana pengadaan sarana dan prasarana yang di sesuaikan dengan keahlian finansial dan kebutuhan yang didapatkan dari data koordinator atau guru kelas terkait sarana dan prasarana yang dibutuhkan oleh TPA dan yang terakhir setelah itu mengambil keputusan akhir terkait penetapan sarana dan prasarana yang akan di adakan dan penanganan terkait sarana dan prasarana yang telah rusak atau tidak berfungsi. Kemudian pada perencanaan (planning) sarana dan prasarana di TPA Cut Muthia hampir sama seperti yang dilakukan di TPA Pinggungan Sebuai, mulai menyusun perencanaan berdasarkan semua usulan dari berbagai pihak yang kemudian akan di bahas dalam sebuah rapat intern membahas terkait pengadaan sarana dan prasarana yang disesuaikan dengan kemampuan finansial dan kebutuhan, namun untuk keputusan terakhir akan di serahkan kepada Kepala TPA itu sendiri untuk di tinjau kembali terkait hasil rapat intern pengadaan sarana dan prasarana dan penanganan terhadap sarana dan prasarana yang sudah tidak berfungsi/rusak. Terdapat perihal yang perlu di maksimalkan kembali yaitu perencanaan sarana dan prasarana harus di kelola secara baik atau secara rutin sehingga dapat memenuhi kebutuhan sarana dan prasarana. Senada dengan teori bahwa perencanaan sarana dan prasarana pendidikan merupakan suatu proses analisis dan penetapan kebutuhan sarana dan prasarana yang di perlukan dengan mempertimbangkan sumber-sumber yang tersedia atau sumber-sumber yang dapat disediakan (Indrawan, 2015).

Pengorganisasian Hasil analisis terkait aktifitas pengorganisasian berdasarkan hasil wawancara dengan (organizing) beberapa guru bahwa kepala TPA Pinggungan Sebuai berperan baik dalam melaksanakan tugas dan juga mempunyai wawasan mengenai pengelolaan sarana prasarana, dalam melaksanakan tugas kepala TPA secara langsung melakukan pemantauan dan pengawasan terhadap proses berlangsungnya kegiatan pendidikan selama pemantauan juga Kepala TPA sesekali memberi arahan dan juga memotivasi kepada guru di dalam kelas. Dan begitu juga Kepala TPA Cut Muthia berperan hal yang sama bertugas dan bertanggung jawab dalam merencanakan, mengarahkan, mengawasi serta melakukan evaluasi dalam proses pengelolaan sarana dan prasarana. Senada dengan teori bahwa kegiatan pengorganisasian dilakukan dengan menetapkan struktur organisasi yang bertanggung jawab dalam mengelola sarana dan prasarana, adapun yang bertanggung jawab dalam mengelola sarana dan prasarana adalah pihak pendidik di setiap kelas itu sendiri (Ananda, 2017).

Pelaksanaan TPA Pinggungan Sebuai dalam proses pelaksanaan inventarisasi hanya dilakukan dengan (actuating) pencatatan sarana dan prasarana pada satu buku inventarisasi tidak dibedakan dalam beberapa buku seperti buku induk inventarisasi, buku penerimaan barang dan buku asalusul barang, akan tetapi dalam pencatatan dilengkapi dengan catatan tentang nama dan jumlah barang, kondisi barang, dan pada sarana dan prasarana yang sudah dicatat dalam buku inventarisasi di berikan kode. Sedangkan pada TPA Cut Muthia sendiri dalam proses pelaksanaan inventarisasi tidak jauh berbeda dengan TPA Pinggungan sebuai yaitu dilakukan dengan pencatatan sarana dan prasarana pada satu buku inventarisasi yang dilengkapi dengan catatan tentang nama dan jumlah barang, kondisi barang namun tidak memberikan kode pada sarana dan prasarana yang sudah dicatat dalam buku inventarisasi sarana dan prasarana. Sesuai dengan teori bahwa pelaksanaan dalam manajemen sarana prasarana akan berjalan dengan baik apabila semua anggota memiliki komitmen yang tinggi dan berpartisipasi dalam mengelola sarana dan prasarana (Ananda, 2017).

Pengawasan (controlling)

TPA Pinggungan Sebuai dan TPA Cut Muthia dalam proses pengawasan sarana dan prasarana dilakukan oleh setiap guru untuk memonitoring atau memantau sarana dan prasarana saat digunakan dalam kegiatan pendidikan. Namun untuk secara keseluruhan Kepala TPA lah yang bertanggung jawab penuh dalam kegiatan monitoring/memantau. Terkait perencanaan sarana dan prasarana sekolah, terdapat beberapa prosedur sebagai berikut: 1) Menyusun berdasarkan semua usulan dari berbagai pihak; 2) Menyusun rencana kebutuhan sarana dan prasarana untuk periode tertentu misalnya satu tahun ajaran; 3) memadukan antara rencana kebutuhan yang telah disusun dengan sarana dan prasarana yang telah tersedia sebelumnya; 4) menyesuaikan dengan dana atau anggaran yang di miliki oleh Lembaga, dalam hal ini jika dana atau anggaran tidak mencukupi maka di perlukannya selekssi terhadap semua kebutuan sarana dan prasarana yang telah direncanakan; 5) mendahulukan rencana kebutuhan sarana dan prasrana yang penting dengan dana atau anggaran yang dimiliki dengan diadakannya seleksi lagi dengan melihat skala perioritas (Ellong, 2018; Jumari, 2019). 
Perencanaan sarana dan prasarana sebagai rangka utama dalam perencanaan kebutuhan sarana dan prasarana (Junaidi \& Danim, 2020). Pengorganisasian (organizing) dilakukan dengan menetapkan struktur organisasi yang bertanggung jawab dalam mengelola sarana dan prasarana (Khikmah, 2020). Pelaksanaan (actuating) dalam manajemen sarana prasarana hendak berjalan dengan baik apabila semua anggota memiliki komitmen yang tinggi dan berpartisipasi dalam mengelola sarana dan prasarana (Suryana, 2020). Pengawasan (controlling) sarana dan prasarana salah satu upaya memantau sarana dan prasarana yang mencakup aktifitas melindungi, memelihara serta memanfaatkan sarana dan prasarana (Kusumawati, 2017). Selengkapnya dapat dilihat pada tabel 1.

Selanjutnya pengadaan sarana dan prasarana dilakukan setelah melakukan rapat penetapan perencanaan sarana dan prasarana yang telah disesuaikan dengan kebutuhan dan juga dana atau anggaran yang kemudian pengadaan sarana dan prasarana di TPA Pinggungan Sebuai cenderung diperoleh dengan metode membeli secara langsung ataupun melakukan pemesanan serta memperoleh sumbangan dari wali murid. senada dengan teori bahwa pengadaan sarana dan prasarana merupakan suatu kegiatan dalam menyediakan berbagai sarana dan prasarana yang disesuaikan dengan kebutuhan dan kemampuan finansial sebagai bentuk realisasi atas perencanaan yang telah dilakukan sebelumnya untuk menunjang proses pendidikan agar berjalan efektif dan efisien sesuai dan mencapai tujuan pendidikan (Murni, 2018).

Taman penitipan anak Pinggungan Sebuai memliki sembilan ruangan yaitu ruang tidur anak yang telah dilengkapi dengan 6 tempat tidur anak dengan bantal guling dan selimut sedangkan TPA Cut Muthia memiliki, ruang guru/administrasi dilengkapi sarana penunjang perkantoran semacam meja guru, rak buku, almari dan lainnya, TPA Pinggungan Sebuai mempunyai dua kamar mandi yaitu kamar mandi untuk anak dan kamar mandi untuk orang dewasa, memiliki dua ruang aktivitas Indoor yang biasa digunakan untuk proses pembelajaran yang dilengkapi dengan APE seperti balok susun besar dan kecil, aneka puzzle, rumah mandi bola dan lainnya, kemudian memiliki ruang aktvitas outdoor yang dilengkapi dengan permainan bola kaki, ayunan, jungkat-jungkit, perosotan, putar-putaran, sedangkan untuk ruang kesehatan juga sudah dilengkapi dengan tempat tidur pasien, kotak P3K, obatobatan, timbangan dan lainnya, TPA Pinggungan Sebuai juga dilengkapi dengan satu ruangan dapur yang di lengkapi sarana seperti alat makan dan lainnya dan juga memiliki gudang digunakan untuk menyimpang barang-barang perlengkapan. Dalam hal ini, pelaksanaan pengadaan sarana dan prasarana pada TPA Pinggungan Sebuai dan TPA Cut Muthia sudah berjalan dengan baik, namun masih mengalami kendala yaitu kurangnya dana dikarenakan hanya mengandalkan dana yang didapat dari wali murid sehingga dalam pengadaan sarana dan prasarana masih terbatas.

Sesuai dengan penelitan terdahulu terkait sarana dan prasara menjadi salah satu fasilitas yang sangat penting dalam proses pendidikan dan tumbuh kembang anak sejak dini (Binsa, 2021). Kemudian salah satu lembaga yang menjadi pilihan para orang tua saat bekerja di luar adalah tempat penitipan anak, tentunya dengan memilih sarana dan prasarana yang sesuai dalam tumbuh kembang anak (Ha, 2020). Adapun Taman Penitipan Anak (TPA) Pinggungan Sebuai dan TPA Cut Muthia dalam proses manajemen sarana dan prasarana secara umum sudah dilaksanakan dengan baik. Namun masih ada beberapa yang perlu di perhatikan dan lebih ditingkatkan. Kemudian diharapkan pada setiap lembaga taman penitipan anak dapat meningkatkan kembali manajemen sarana dan prasarana yang baik, karena sarana dan prasarana merupakan salah satu sumber daya yang penting dalam menunjang proses tumbuh kembang anak usia dini selama berada di taman pentipan anak. 


\section{SIMPULAN}

Adapun kesimpulan dari hasil analisis terhadap manajemen POAC di Taman Penitipan Anak (TPA) Pinggungan Sebuai dan TPA Cut Muthia dalam proses manajemen sarana dan prasarana secara umum sudah dilaksanakan dengan baik melalui seluruh kegiatan manajemen secara rinci yang meliputi perencanaan (planning), pengoranisasian (organizing), pelaksanaan (actuating) dan pengawasan (controlling) (POAC). Oleh karena itu, dengan meningkatkan kembali manajemen sarana dan prasarana melalui kegiatan manajemen yang tepat pada taman penitipan anak menjadi salah satu sumber daya yang penting dalam menunjang proses tumbuh kembang anak usia dini.

\section{UCAPAN TERIMA KASIH}

Penulis mengucapkan terimakasih kepada UIN Raden Intan Lampung dan LP2M UIN Raden Intan Lampung yang telah memberi dukungan sehingga penelitian ini dapat diselesaikan.

\section{DAFTAR PUSTAKA}

Agustina, F. (2019). Penanaman Pendidikan Karakter Dan Metode Story Telling. Jurnal: Penelitian Medan Agama, 10(2).

Ananda, R. (2017). Manajemen Sarana dan Prasarana Pendidikan. CV. Widya Puspita.

Beauvais, C. (2016). Ages and ages: The multiplication of children's 'ages' in early twentiethcentury child psychology. History of Education, 45(3), 304-318. https:// doi.org/10.1080/0046760X.2015.1136359

Binsa, U. H. (2021). Manajemen Sarana Prasarana Pendidikan Anak Usia Dini di TK Pelangi Anak Negeri Yogyakarta. Jurnal CARE, 8(2), 1-10.

Brebner, C., Hammond, L., Schaumloffel, N., \& Lind, C. (2015). Using relationships as a tool: early childhood educators' perspectives of the child-caregiver relationship in a childcare setting. Early Child Development and Care, 185(5), 709-726. https:// doi.org/10.1080/03004430.2014.951928

Ellong, T. D. A. (2018). Manajemen Sarana dan Prasarana di Lembaga Pendidikan Islam. Jurnal Pendidikan Islam Iqra', 11(1), 1-8. https:// doi.org/10.30984/jii.v11i1.574

Esha, M. I. K., \& Abtokhi, A. (2020). Guruku Sayang, Guruku Berkembang: Problem Mapping Model dalam Proses Pengembangan Pendidikan Anak Usia Dini (PAUD). Engagement: Jurnal Pengabdian Kepada Masyarakat, 4(1), 066-081. https:// doi.org/10.29062/engagement.v4i1.178

Falhatunnisa, I., Santika, T., \& Sutarjo. (2020). Persepsi Keluarga Tentang Pentingnya Pendidikan Anak Usia Dini dalam Pembentukan Karakter. JoCE; Journal of Community Education, 1(1), 1-6.

Ha, K. M. (2020). Conceptualization of Major Stakeholders in Emergency Management of Childcare Facilities. Journal of Evidence-Based Social Work (United States), 17(5), 514526. https:// doi.org/10.1080/26408066.2020.1768192

Hadi, S. (2020). Model pengembangan mutu di lembaga pendidikan. Jurnal Pendidikan Dan Ilmu Sosial, 2(3), 321-347.

Hamer, W., Rachman, T. A., Lisdiana, A., Wardani, W., Karsiwan, K., \& Purwasih, A. (2020). Potret Full Daycare sebagai Solusi Pengasuhan Anak bagi Orang Tua Perkerja. Tapis : Jurnal Penelitian Ilmiah, 4(1), 75. https:// doi.org/10.32332/tapis.v4i1.1955

Hardiyanti, D. (2020). Apakah Kualitas Penitipan Anak itu Penting? Sebuah Gambaran Perkembangan untuk Pendidikan Anak Usia Dini. Sentra Cendekia, 1(1), 1-7. https://doi.org/10.30651/pedagogi.v5i1.2605

Jumari. (2019). Urgensi Manajemen Sarana dan Prasarana Berkualitas dalam Meningkatkan $\begin{array}{lllll}\text { Kreativitas Peserta } & \text { Didik. } & \text { Widya } & \text { Balina, } & 4(7) \text {. } \\ \text { https://doi.org/10.31227/osf.io/xj2b5 }\end{array}$ 
Junaidi, U., \& Danim, S. (2020). Implementasi Manajemen Sarana dan Prasarana Pendidikan di SMA Negeri 10 Bengkulu Selatan. Jurnal Manajemen Pendidikan, 14(1), 72-83. https://doi.org/10.17509/edukid.v14i1.17093

Khikmah, N. (2020). Manajemen Sarana dan Prasarana Untuk Mengembangkan Mutu Pendidikan. Jurnal Administrasi Dan Manajemen Pendidikan, 3(2), 123-130. https://doi.org/10.17977/um027v3i22020p123

Koedel, C., Li, J., Springer, M. G., \& Tan, L. (2019). Teacher Performance Ratings and Professional Improvement. Journal of Research on Educational Effectiveness, 12(1), 90115. https:// doi.org/10.1080/19345747.2018.1490471

Kustiawan, A. A., \& Enggarwati, S. A. (2021). Pengaruh Pembelajaran Berbasis Permainan Online Terhadap Kecerdasan Fisik Motorik Anak Usia Dini. Journal of Early Childhood and Character Education, 1(1), 91-106. https://doi.org/10.21580/joecce.v1i1.6619

Kusumawati, D. (2017). Manajemen Sarana Prasarana Di Day Care Baby'S Home Salatiga. Scholaria: Jurnal Pendidikan Dan Kebudayaan, 7(1), 17. https://doi.org/10.24246/j.scholaria.2017.v7.i1.p17-25

Lee, S. H. (2016). Has childcare become less of a burden in South Korea? Exploring the nature of pre-and post-reform childcare provision. Asian Journal of Women's Studies, 22(4), 414-442. https:/ / doi.org/10.1080/12259276.2016.1242941

Megasari, R. (2014). Peningkatan Pengelolaan Sarana dan Prasarana Pendidikan Untuk Meningkatkan Kualitas Pembelajaran di SMPN 5 Bukit Tinggi. Jurnal Administrasi Pendidikan, 2(1), 636-831. https:// doi.org/10.24042/alidarah.v8i1.3088

Murni. (2018). Mnaajemen Sarana dan Prasarana Pendidikan. Jurnal Mimbar Akademika, 2(2), 65-82.

O'Hara, M. (2010). Positive highlights on quality daycare for children: A North West of Ireland study. Child Care in Practice, 16(4), 359-375. https://doi.org/10.1080/13575279.2010.498163

Oktaviana, M. E., \& Utsman. (2015). Proses Pengasuhan Taman Penitipan Anak (Studi pada Taman Penitipan Anak Dewaruci Kids Kecamatan Demak Kabupaten Demak). Journal of Non Formal Education and Community Empowerment, 4(2), 121-126.

Parid, M., \& Alif, A. L. S. (2020). Pengelolaan Sarana dan Prasarana Pendidikan. Jurnal Tafhim Al-Ilmi, 11(2), 266-275. https:/ / doi.org/10.37459/tafhim.v11i2.3755

Plum, M. (2017). Making 'what works' work: enacting evidence-based pedagogies in early childhood education and care. Pedagogy, Culture and Society, 25(3), 375-388. https://doi.org/10.1080/14681366.2016.1270349

Pricilia, A., Abdurrahman, A., \& Herlina, K. (2020). Teacher expectation towards interactive multimedia integrated with STEM in learning physics: Preliminary study on geometry optic learning material. Journal of Physics: Conference Series, 1572(1). https:// doi.org/10.1088/1742-6596/1572/1/012065

Riyadlotus Sholichah. (2020). Pengasuhan Berbasis Neurosain dan Kecerdasan Emosi dalam Pengasuhan Anak Usia Dini. Atthiflah: Journal of Early Childhood Islamic Education, 7(1), 19-28.

Rizkita, D. (2017). Pengaruh Standar Kualitas Taman Penitian Anak (Tpa) Terhadap Motivasi Dan Kepuasaan Orangtua (Pengguna) Untuk Memilih Pelayanan Tpa Yang Tepat. Early Childhood: Jurnal Pendidikan, 1(1), 28-43. https://doi.org/10.35568/earlychildhood.v1i1.46

Rohmani, N. (2020). Analisis Angka Partisipasi Kasar Pendidikan Anak Usia Dini (PAUD) di Seluruh Indonesia. Jurnal Obsesi: Jurnal Pendidikan Anak Usia Dini, 5(1), 625. https://doi.org/10.31004/obsesi.v5i1.262

Rosmayati, S., Maulana, A., Sauri, S., \& Barlian, U. C. (2021). Pengelolaan Pembelajaran Dalam Proses Pengembangan Sosial Emosional Standar Pendidikan Anak Usia Dini. 
Coopetition: Jurnal Ilmiah Manajemen, XII(1), 45-54. https://doi.org/10.32670/coopetition.v12i1.215

Schmidt, T., Smidt, W., \& Roux, S. (2018). What do pedagogues in daycare do? Empirical analyses of the occupational activities of pedagogues in children's daycare centres in Germany. European Early Childhood Education Research Journal, 26(3), 446-460. https://doi.org/10.1080/1350293X.2018.1463910

Suryana, A. T. (2020). Teori dan Praktik Manajemen Sarana dan Prasarana Pesantren. Jurnal Ilmu-Ilmu Agama, 2(1), 44-59. https://doi.org/10.51482/almujaddid.v2i2.42

Trianingsih, E., Arsi, A. A., \& Artikel, I. (2020). Model Pengelolaan Pendidikan dan Bentuk Layanan Taman Penitipan Anak Islam Terpadu (TPAIT) Abu Bakar Ash Shidiq Juwana dalam Menggantikan Peran Keluarga. Solidarity: Journal of Education, Society and Culture, 9(1), 892-905.

Ulfa, M., Ismail, H., \& Ariani, S. S. (2021). Pengelolaan Sarana Dan Prasarana Pendidikan Di SDN 03 Kembang Kerang Daya Kecamatan Aikmel Lombok Timur. Jurnal Manajemen Dan Budaya STAI Darul Kamal NW Kembang Kerang, 1(1), 35-42. https:// doi.org/10.37459/tafhim.v11i2.3755

Yula Anggriani. (2020). Pemanfaatan Gadget dalam Meningkatkan Minat Baca Anak di Keluarga. Jurnal Perpustakaan Universitas Airlangga, 10(2), 138-147. https:// doi.org/10.20473/jpua.v10i2.2020.138-147 